\title{
Failure mechanics of slope slip with predestinate slip plane
}

\author{
J. Vacek \& S. Sedláčková \\ Czech Technical University in Praha, Czech Republic
}

\begin{abstract}
Failure of rock mass is not a static process, but has its own history. Its duration varies from several seconds to several hundred years. Rock mass movements are often measured in hundreds of metres and significantly change the formation's original shape. Failure mechanics can be studied experimentally. On nonhomogeneous models we can observe the onset of failure (prior to and during the failure, deformations increase on sliding surfaces), the chronology of various stages of failure (cavings, slides), and the final shape of the rock mass. We can also observe influences exerted by modelled joints, adits and other features upon the failure history and shapes of cavings and slides.

Research will be concentrated on the stability of internal tailings of Northern Bohemia open coal mines. Tailings will be strengthened by piles that join bed rock with tailing over the predestinated slip plane.

Methods used for the study of geotechnical problems have to allow for two basic presumptions:

- results must be time dependent

- results must allow the creation of joints in the rock mass before the study event and during the event must allow for the moving of rock along joints, the opening of joints and creation of new joints. The direction of modelled joints must be similar to reality, i.e. their direction and inclination must be the same as the real ones. These measures make it possible to create the structure of modelled rock mass similar to real ones. Filling of cracks must be equivalent to real ones.
\end{abstract}

A scale physical model from equivalent materials and mathematical solutions were used as a basic method for the study of geotechnical problems.

Keywords: failure mechanics, failure history, physical model, mathematical model, stability of rock mass, jointed rock mass. 


\section{Introduction}

The present study is concerned with the failure mechanics of the slope build-up on the bedrock with a smooth surface. This arrangement is typical for the internal tailings in the surface of coal mines. The experimental study was constructed in a stand enabling tilting. A scale model was constructed from equivalent materials. The smooth surface was made from a special epoxy resin. For the mathematical part, the particle flow code in 2 dimensions (PFC2D) was employed. The pile bored to the bedrock, instrumented with strain gauges, restrain the slope movement in the experimental case. Ten fixed balls were considered in the mathematical solution. Both methods have shown the slip as a time dependent process. Moreover, both methods allow one to describe a decomposition of the originally homogeneous and isotropic body into blocks (see figs 2-3) and, therefore, they treat the slip as a discontinuous deformation process.

The stability of mine tailings situated on an inclined terrain is often influenced by a predestinated slip surface represented by the contact between the terrain surface and tailings. The speed of movements of Loket or Vintírov tailings during the slip was about $1 \mathrm{~m}$ in a day. For strengthening of the critical shear plane, piles were bored down to the bedrock and jointed the tailings with the original terrain. In fig. 1 the case of slip of terrain along predestined slip plane (Hasen, 1969, Mencl [4]) is shown; it was created by sensitive clays.

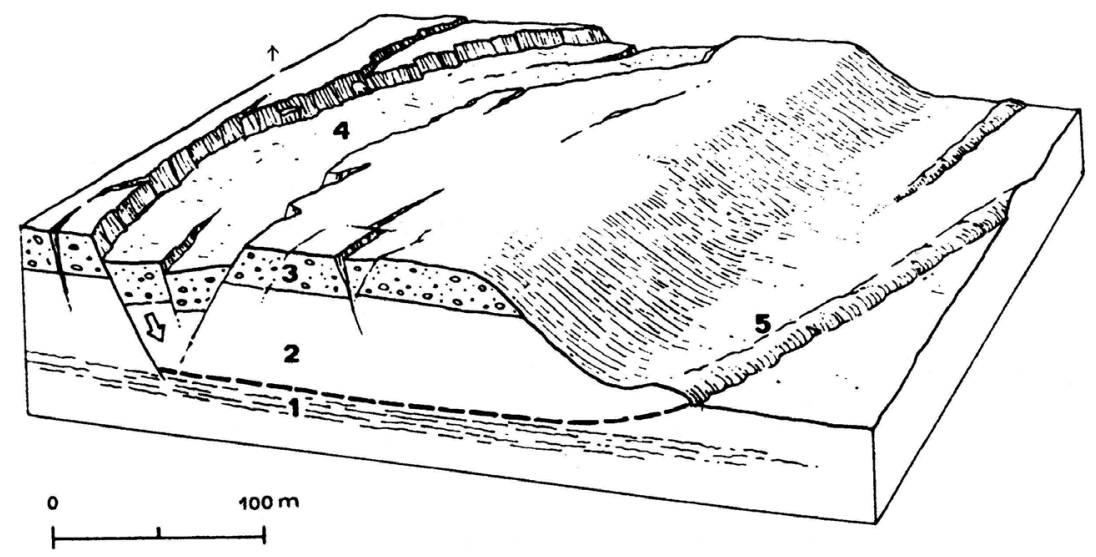

1. Sensitive sea clays, 2. Rigid clays, 3. Sands and gravels, 4. Fall down hedge shape disconnected place, 5 . Squeezing out clays

Figure 1: Block diagram of slip along sensitive clays during an earthquake in Alaska in 1964 year. 


\section{Experimental models}

Physical scale models from equivalent materials were utilized for an experimental study of the problem. The model was built-up from three types of material: the bedrock consisted of a mixture of 100 weight parts of melted limestone, 4 w.p. of cement and 4 w.p. of water. The shear surface was created by a specifically adapted epoxy resin. The angle of internal friction and the long time cohesion equals zero. It behaves as a liquid with a high viscosity. Tailings were made from a mixture of melted limestone 100 w.p. and grease 0,5 w.p.. The pile was represented by a polyethylene pipe with an $18 \mathrm{~mm}$ diameter, provided with three pairs of strain gauges connected to the tensometrical bridge. This arrangement enables measure of the force with which the pile resists the tailings slip. The model dimensions were: length $-1450 \mathrm{~mm}$, height $-600 \mathrm{~mm}$, width $200 \mathrm{~mm}$. Before the test, the stand was tilted $10^{\circ}$ from the horizontal plane (see figure 2).

\section{Test results}

Figure 2 represents a photograph of the model before the test. Figure 3 shows the model at a time $t_{o}+30$ minutes. Figure 4 depicts the model at a time $t_{o}+70 h$ and figure. 5 at a time $t_{o}+140 \mathrm{~h}$. The photos clearly reveal the cracks in the tailing's body. Figure 5 also shows the movements of the tailing body and the flow of the tailings material around the pile. Figure 6 shows the slip history as obtained from the experimental part of the solution by the method of a close stereophotogrammetry and depicted by a technocart device. It records the individual stages of the model. Figure 7 displaces a change of the slip surface. In Figure 8, there are seen the movements of selected points. As shown in figure 8, there are three areas with different movements during the slip. The part under the last right crack has only small, horizontal displacements. The left triangle under the last left crack moves only in the horizontal direction, and the wedge between these areas moves parallel with the last right crack.

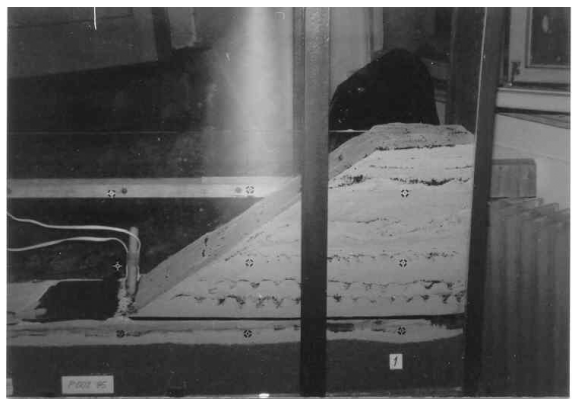

Figure 2: $\quad$ Model before test $\mathrm{t}_{\mathrm{o}}=\mathrm{O}$.

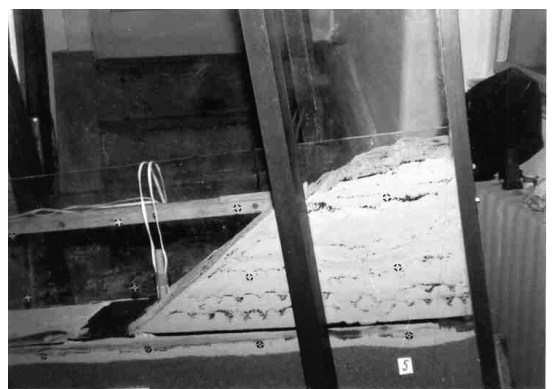

Model at a time $\mathrm{t}_{\mathrm{o}}+30 \mathrm{~min}$. 

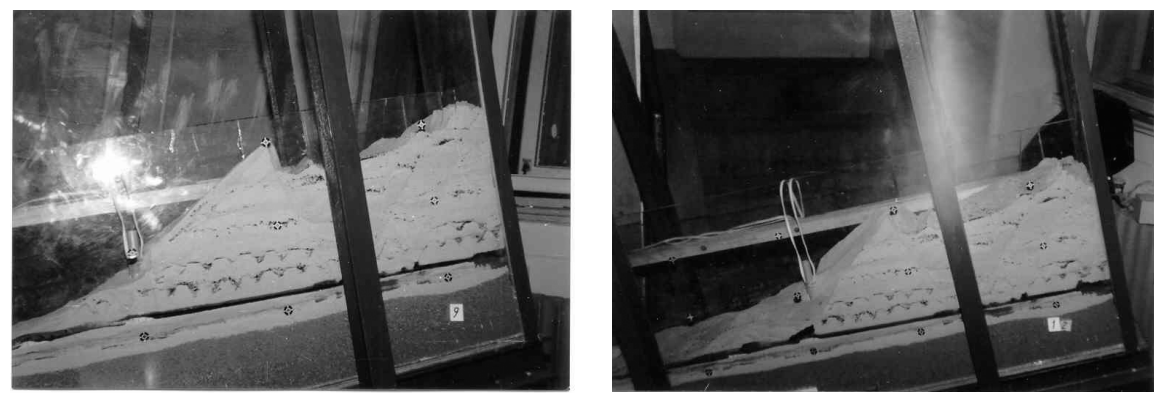

Figure 4: Model at a time $t_{0}+70 h$. Figure 5: Model at a time $\mathrm{t}_{\mathrm{o}}+140 \mathrm{~h}$.

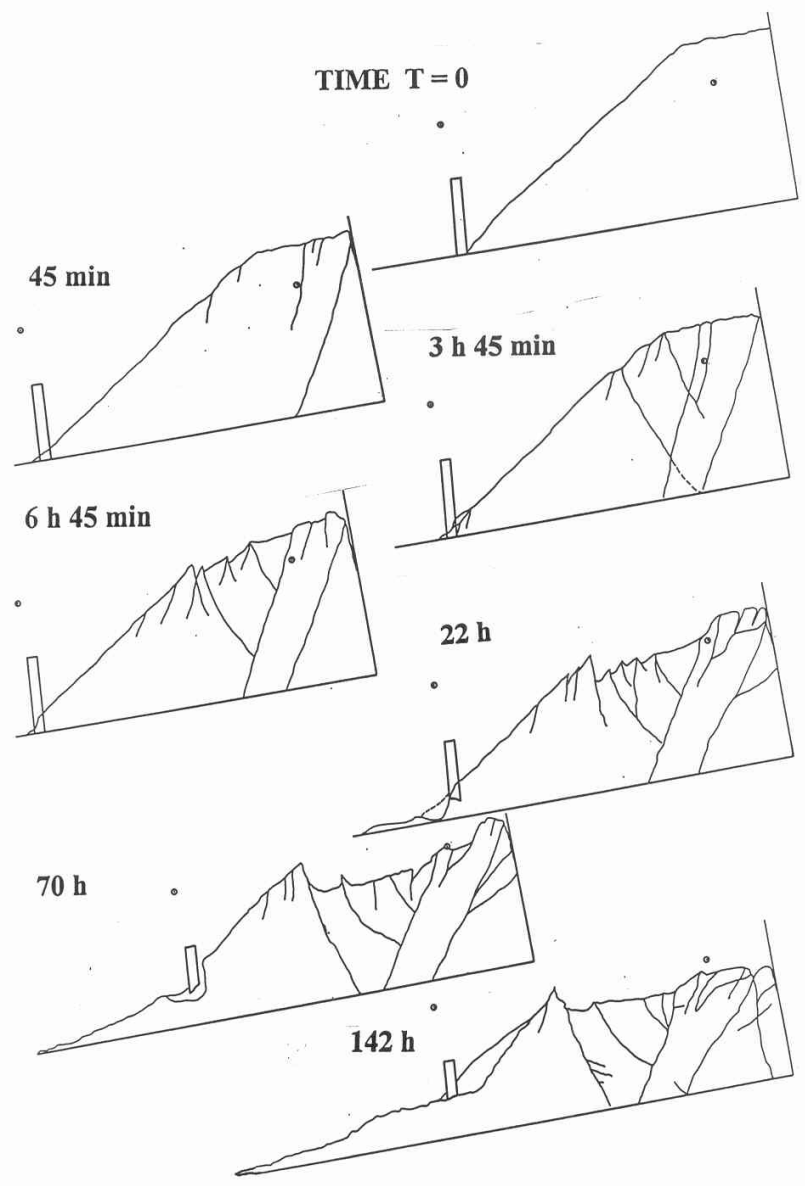

Figure 6: Decomposition of slope during slip.

WIT Transactions on Engineering Sciences, Vol 57, (C) 2007 WIT Press www.witpress.com, ISSN 1743-3533 (on-line) 


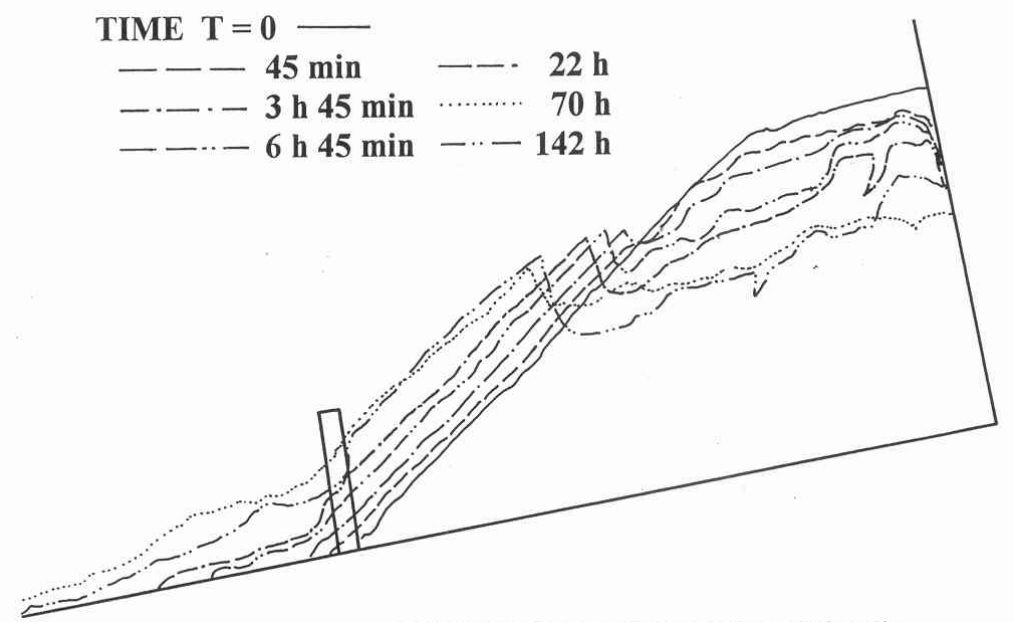

Figure 7: Changes of tailing surface during slip.

TIME $\mathbf{T}=\mathbf{0}$

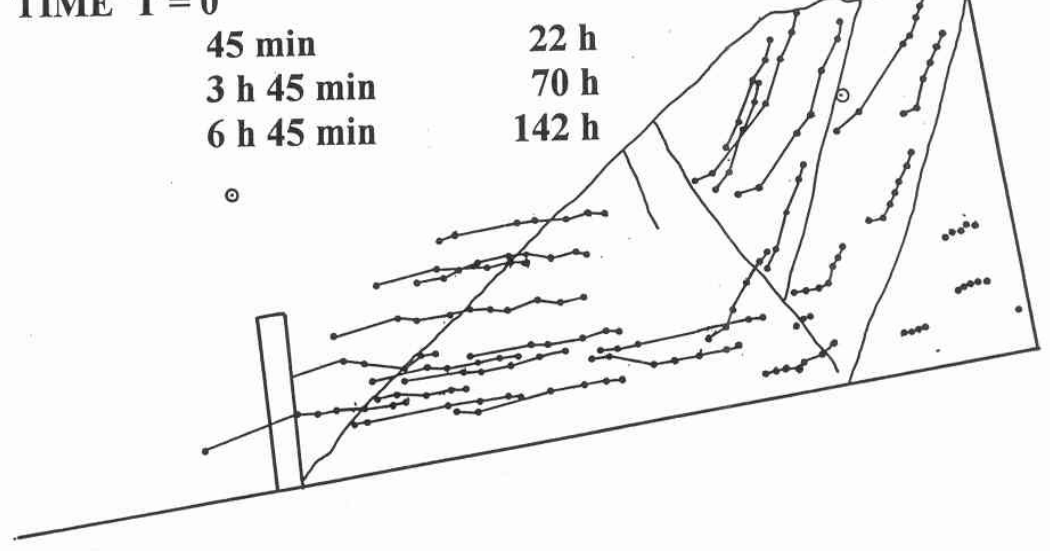

Figure 8: $\quad$ Moving of selected points during slip. 


\section{Mathematical part}

For the numerical modeling study $\mathrm{PFC}^{2 \mathrm{D}}$ software (Particle Flow Code in two dimensions) was used. In this code rock mass is composed from balls (in two dimensions from discs). Each disc has its own diameter and axial and shear stiffness. Among the discs axial and shear bonds act. When stresses in some area exceed bonds, discs are disconnected and a joint appears. Each property (diameter, stiffness...) is arbitrary and it is possible to order them properties in the conditions Gauss statistical dispersion. It is possible to fix every disc against moving or rotation. The pile was modelled as ten fixed disc, the diameters and distance was carefully studied because arrangement must allow floating disc of rock mass between them, but the pile must defend the slope slip similar to that in the physical model.

Calculation runs in separate cycles (iterations). Unbalanced force is characterized after each cycle degree of slope settlement. When it reaches the request value, work is finished. In the case described it was after 800000 cycles. Some of the calculate states are shown in fig. 9.

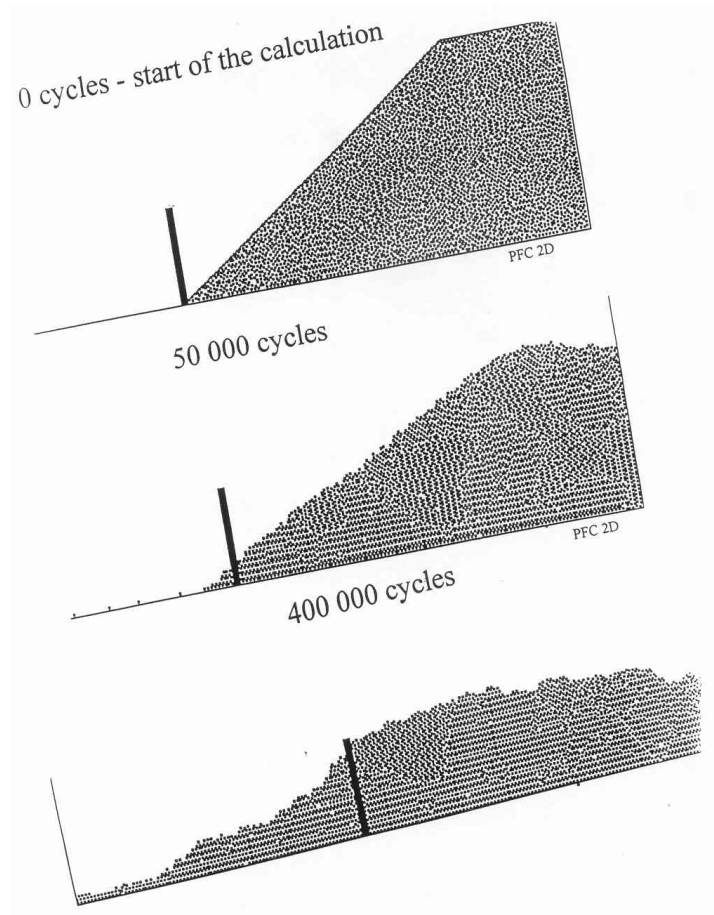

Figure 9: $\quad$ Slip of tailings according $\mathrm{PFC}^{2 \mathrm{D}}$ Code. 
Computational Methods and Experiments in Materials Characterisation III 419

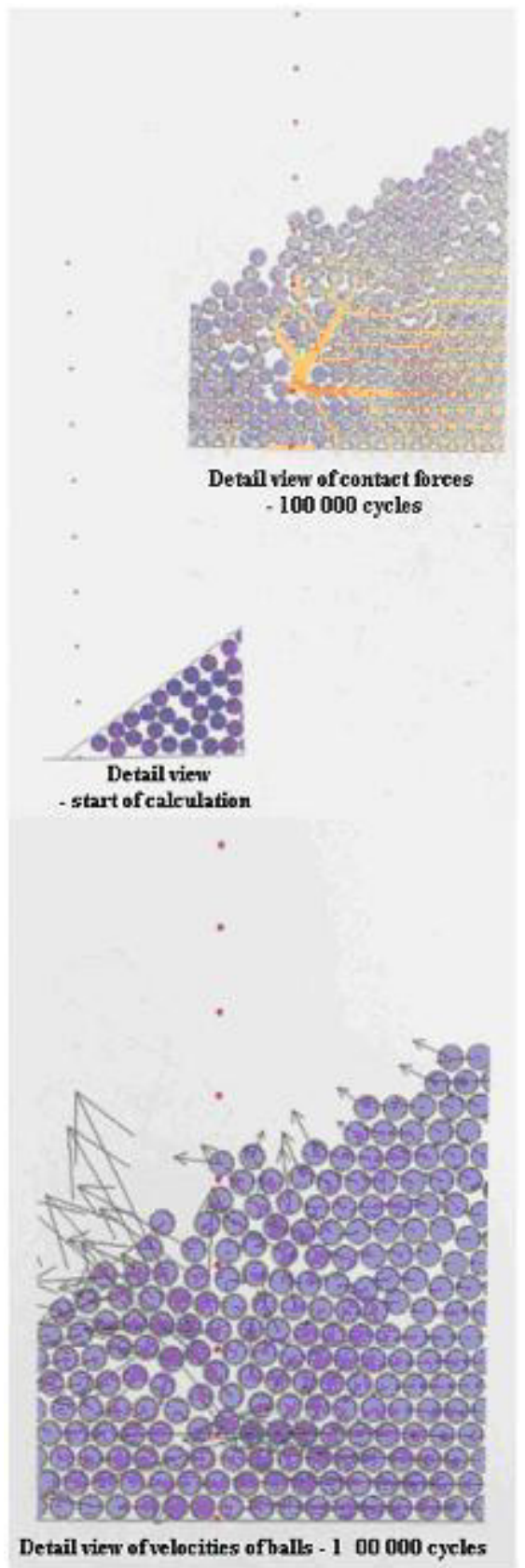

Figure 10: Details of the velocities of individual discs. 


\section{Conclusions}

For solving geotechnical problems, it is modern and convenient to use a coupled modeling, with a mathematical and experimental part. This arrangement makes it possible to cut down the disadvantages of each method. They thus offer a description of the problem that is much closer to reality.

Both methods described allow investigation of the slope slip problem as a time-dependent process and treatment of this problem as a discontinuous deformation process (which when modelled and during slip created new cracks).

The estimation of the force defended in the slope slip by the pile was also proved in the terrain.

\section{Acknowledgement}

This research has been sponsored by the GAČR: 103/05/0334.

\section{References}

[1] Vacek, J. (1992) Similarity in geotechnics and calibration of models from equivalent materials. Rock mechanics as a multidisciplinary science, Oklahoma, Balkema, p. 745-754.

[2] Vacek, J., Westman, E. (1996) Experimental Study of Rock Mass Decomposition During Slip. IF DDA, Berkeley, California.

[3] Vacek, J., Sedláčková, S. (2006) Failure mechanics of jointed rock mass, Debris Flows, Rhodos, Witpress, Southampton, p. 251-260

[4] Mencl, V. (1974) Inženýrská geologie (Engineering geology), Academia, Praha, 507 p. 